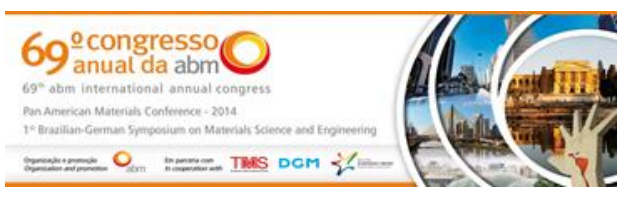

Tema: Materiais cerâmicos, compósitos e poliméricos

\title{
MICROSTRUCTURAL AND MAGNETIC CHARACTERIZATION OF A Co-Mn FERRITE*
}

\author{
Vera Lúcia Othéro de Brito ${ }^{1}$ \\ Stéphanie Alá Cunha² \\ Mateus Botani de Souza Dias ${ }^{3}$ \\ Cristina Bormio Nunes ${ }^{4}$
}

\begin{abstract}
Literature has shown that spinel Co-Mn ferrite have potential application in magnetomechanical sensors, due to its relatively high magnetoelastic sensitivity. In this work, $\mathrm{Co}-\mathrm{Mn}$ ferrite was processed by means of the ceramic method, using $\mathrm{Fe}_{2} \mathrm{O}_{3}, \mathrm{MnO}$ and $\mathrm{Co}_{3} \mathrm{O}_{4}$ as raw materials. Samples were liquid-phase sintered, using $\mathrm{Bi}_{2} \mathrm{O}_{3}$ additive as liquid-phase former. X-ray fluorescence analysis was carried out in the raw materials in order to evaluate their impurity content. Atomic absorption spectrometry analysis was used for quantifying the Co/Mn/Fe proportion in the ferrite. The microstructure of the sintered sample was analyzed by means of Scanning Electron Microscopy. The magnetization and magnetostrictive behavior of the ferrite were evaluated, obtaining curves for magnetic hysteresis, magnetostriction and magnetoelastic sensitivity. The impurity inclusions and the Bi-rich particles formed from the liquid phase were characterized. The sintered ferrite had a total magnetostriction of -126ppm, which is lower than the values reported in literature for a Co-Mn ferrite of similar composition. It was verified that sintering was carried out within a critical temperature range, in which the decomposition of $\mathrm{Mn}$ ferrites may occur when sintering in air. This decomposition affects the magnetic properties of the material, and it may be avoided by using controlled sintering atmospheres.
\end{abstract}

Keywords: Magnetic ceramics; Ferrites; Magnetostriction; Magnetic properties.

1 Ph.D., Technologist, Divisão de Física Aplicada, Instituto de Estudos Avançados, São José dos Campos, SP, Brazil.

2 B.Sc., Master's student, Divisão de Física Aplicada, Instituto de Estudos Avançados, São José dos Campos, SP, Brazil.

3 B.Sc., Master's student, Faculdade de Engenharia Química de Lorena, Universidade de São Paulo, Lorena, SP, Brazil.

4 Ph.D., Professor, Faculdade de Engenharia Química de Lorena, Universidade de São Paulo, Lorena, SP, Brazil.

${ }^{*}$ Contribuição técnica ao 69 Congresso Anual da ABM - Internacional e ao $14^{\circ}$ ENEMET - Encontro Nacional de Estudantes de Engenharia Metalúrgica, de Materiais e de Minas, 21 a 25 de julho de 2014, São Paulo, SP, Brasil. 


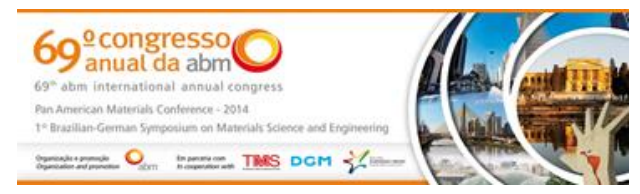

\section{INTRODUCTION}

Cobalt ferrite $\left(\mathrm{CoFe}_{2} \mathrm{O}_{4}\right)$ have a relatively high magnetostriction $(\lambda)$, with saturation values usually exceeding 200ppm. The substitution of $\mathrm{Co}$ and Fe for other elements, such as $\mathrm{Mn}, \mathrm{Ge}, \mathrm{Al}, \mathrm{Zn}$ and $\mathrm{Ga}$ may increase the magnetoelastic sensitivity of the material [1-7], which may be evaluated by means of the parameter $\mathrm{d} \lambda / \mathrm{dH}$. The magnetostrictive properties of these ferrites indicate a potential application in stress and force sensors. Some authors [1,8] have demonstrated that the magnetic hysteresis of a cobalt ferrite may be reduced by means of the substitution of Fe by $\mathrm{Mn}$, also reducing the Curie temperature of the material and maintaining good magnetostrictive properties. Literature $[9,10]$ have demonstrated that the substitution of Co for Mn may may favor the magnetic properties of Co ferrite for sensors applications; $\mathrm{Co}_{0.7} \mathrm{Mnn}_{0 .} \mathrm{Fe}_{2} \mathrm{O}_{4}$ seems to be the best composition for this purpose.

Liquid-phase sintering is a sintering method that allows the reduction of the sintering temperatures of ceramics, by means of the enhanced diffusion and the capillary forces that are developed when sintering in the presence of a liquid phase. $\mathrm{Bi}_{2} \mathrm{O}_{3}$ is one of the commonly used additives as liquid-phase former and literature [11] have shown its effectiveness in obtaining dense ferrites with sintering temperatures lower than $1000^{\circ} \mathrm{C}$.

In this work, a Co-Mn ferrite was processed by means of the ceramic method and liquid-phase sintered with $\mathrm{Bi}_{2} \mathrm{O}_{3}$ addition. Our objective is to characterize the microstructure and the chemical homogeneity of the sample obtained. The morphology of the phases formed are evaluated, including of those originated from contaminants. The magnetic properties of the sample were compared to the data reported in literature for Co-Mn ferrites of similar composition.

\section{MATERIALS AND METHODS}

The ferrite was processed by means of the ceramic method, using $\mathrm{Fe}_{2} \mathrm{O}_{3}, \mathrm{MnO}$, and $\mathrm{Co}_{3} \mathrm{O}_{4}$ as raw materials. X-ray fluorescence analysis was carried out in the raw materials in order to evaluate their impurity content.

The raw materials were dry-mixed in an agathe mortar and calcined at $850^{\circ} \mathrm{C}$ for $4 \mathrm{~h}$. The calcined powder was evaluated by means of X-ray diffraction (XRD), with Cu Ka radiation. Atomic absorption spectrometry analysis was carried out for determination of the $\mathrm{Fe} / \mathrm{Co} / \mathrm{Mn}$ proportion of the calcined powder. $0.6 \mathrm{~mol} \% \mathrm{Bi}_{2} \mathrm{O}_{3}$ was added to the powder and it was wet mixed/grinded in an eccentric mill for $1 \mathrm{~h}$.

The milled powder was uniaxially compacted with $50 \mathrm{MPa}$ in $8 \mathrm{~mm}$ pellets and subsequently isostatically compacted with $300 \mathrm{MPa}$. The pellets were sintered at $950^{\circ} \mathrm{C} / 24 \mathrm{~h}$ in air. The density of the sintered pellets was evaluated by means of the Archimedes' method and their microstructure were evaluated by means of scanning electron microscopy (SEM). The sample for SEM was grinded, polished and thermally etched at $850^{\circ} \mathrm{C}$ for $10 \mathrm{~min}$.

For magnetic characterization, a $2.63 \times 2.41 \times 1.86 \mathrm{~mm}$ sample was cut from a sintered pellet. The magnetic characterization was carried out by means of vibrating sample magnetometry (VSM) and capacitance dilatometry [12]. From the magnetostriction results obtained by means of capacitance dilatometry, the following parameters were measured (parallel $(/ /)$ and perpendicular $(\perp)$ to the magnetic field $(H))$ :

- Saturation magnetostriction: $\left(\lambda_{/ /}\right)_{\mathrm{s}}$ and $\left(\lambda_{\perp}\right)_{\mathrm{s}}$.

- Total magnetostriction: $\lambda_{\text {tot }}=\left(\lambda_{/} /\right)_{\mathrm{s}}-\left(\lambda_{\perp}\right)_{\mathrm{s}}$

${ }^{*}$ Contribuição técnica ao $69^{\circ}$ Congresso Anual da ABM - Internacional e ao 14을 ENEMET - Encontro Nacional de Estudantes de Engenharia Metalúrgica, de Materiais e de Minas, 21 a 25 de julho de 2014, São Paulo, SP, Brasil. 


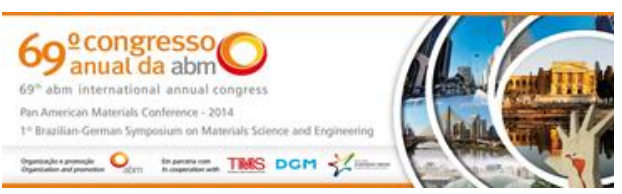

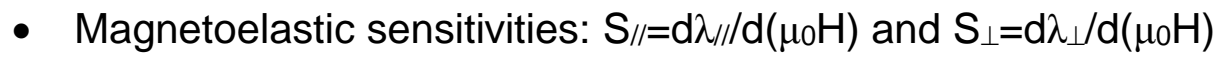

\section{RESULTS AND DISCUSSION}

Table 1 shows the results of the X-ray fluorescence analysis of the raw materials. The contaminants with highest fractions in the raw materials' mixture are $\mathrm{SO}_{3}$, and $\mathrm{BaO}$ (indicated in red on Table. 1).

Table 1: Results (in wt\%) from the $\mathrm{X}$-ray fluorescence analysis of the $\mathrm{MnO}, \mathrm{Fe}_{2} \mathrm{O}_{3}$, and $\mathrm{Co}_{3} \mathrm{O}_{4}$ raw materials.

\begin{tabular}{|c|c|c|c|}
\hline Substance & $\mathrm{Co}_{3} \mathrm{O}_{4}$ & $\mathrm{Fe}_{2} \mathrm{O}_{3}$ & $\mathrm{MnO}$ \\
\hline $\mathrm{Co}_{3} \mathrm{O}_{4}$ & 97.61 & - & - \\
\hline $\mathrm{MnO}_{\mathrm{Fe}} \mathrm{O}_{3}$ & - & 0.24 & 94.71 \\
\hline $\mathrm{MnO}$ & 0.30 & 99.05 & 0.98 \\
\hline $\mathrm{F}$ & 0.86 & - & - \\
\hline $\mathrm{NiO}$ & 0.80 & - & - \\
\hline $\mathrm{Cr}_{2} \mathrm{O}_{3}$ & 0.30 & - & - \\
\hline $\mathrm{SiO}_{2}$ & 0.03 & 0.05 & 0.26 \\
\hline $\mathrm{ZnO}_{\mathrm{SO}}$ & 0.04 & 0.12 & 0.14 \\
\hline $\mathrm{Al}_{2} \mathrm{O}_{3}$ & 0.03 & - & 0.77 \\
\hline $\mathrm{CaO}_{\mathrm{P}_{2} \mathrm{O}_{5}}$ & - & 0.28 & 0.24 \\
\hline $\mathrm{BaO}$ & - & 0.13 & 0.07 \\
\hline $\mathrm{Na}_{2} \mathrm{O}$ & - & 0.09 & 0.06 \\
\hline $\mathrm{MgO}$ & - & 0.04 & 2.24 \\
\hline $\mathrm{K}_{2} \mathrm{O}$ & - & - & 0.39 \\
\hline & - & - & 0.07 \\
\hline
\end{tabular}

The results from the atomic absorption spectrometry analysis of the calcined powder are shown on Table 2, indicating a Co:Mn:Fe atomic proportion of 0.65:0.29:2.06.

Table 2. Results of the chemical analysis of the calcined powder (wt\%)

\begin{tabular}{|c|c|c|}
\hline Co & $M n$ & Fe \\
\hline $15.6 \pm 0.8$ & $6.40 \pm 0.16$ & $46.5 \pm 0.8$ \\
\hline
\end{tabular}

Figure 1 shows the X-ray diffractogram of the sintered pellet, evidencing the presence of $\mathrm{Fe}_{2} \mathrm{O}_{3}$ (hematite). The calculated lattice parameter of the spinel phase was $8.395 \AA$. The lattice parameters measured by Bhame [11] in $\mathrm{Co}_{1-x} \mathrm{Mn}_{x} \mathrm{Fe}_{2} \mathrm{O}_{4}$ were 8.393 $\AA$ for $x=0.2$ and $8.400 \AA$ for $x=0.3$ (our target composition). Using the lattice parameter "a" of $8.400 \AA$ in (1) [13], it is possible to estimate the mass density of a pore-free $\mathrm{Co}_{0.7} \mathrm{Mnn}_{0.3} \mathrm{Fe}_{2} \mathrm{O}_{4}$ as $5.23 \mathrm{~g} / \mathrm{cm}^{3}$. In (1), $\mathrm{M}$ is the molar mass of $\mathrm{Co}_{0.7} \mathrm{Mn}_{0.3} \mathrm{Fe}_{2} \mathrm{O}_{4}$ and $\mathrm{N}$ is the Avogadro's number. Since the measured mass density of the sintered pellet was $5.07 \mathrm{~g} / \mathrm{cm}^{3}$, it is possible to verify the effectiveness of the liquid-phase sintering, in terms of attaining low porosity at low sintering temperatures: in a previous work [14], dilatometry tests demonstrated that the sintering temperature in which highest densities are expected for this Co-Mn ferrite is between 1250$1300^{\circ} \mathrm{C}$.

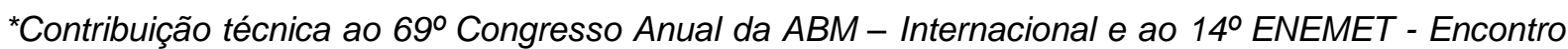
Nacional de Estudantes de Engenharia Metalúrgica, de Materiais e de Minas, 21 a 25 de julho de 2014, São Paulo, SP, Brasil. 


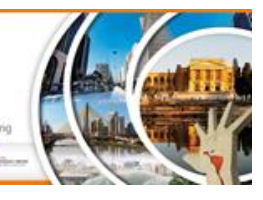

$$
\mathrm{d}=\frac{8 \mathrm{M}}{\mathrm{Na}^{3}}
$$

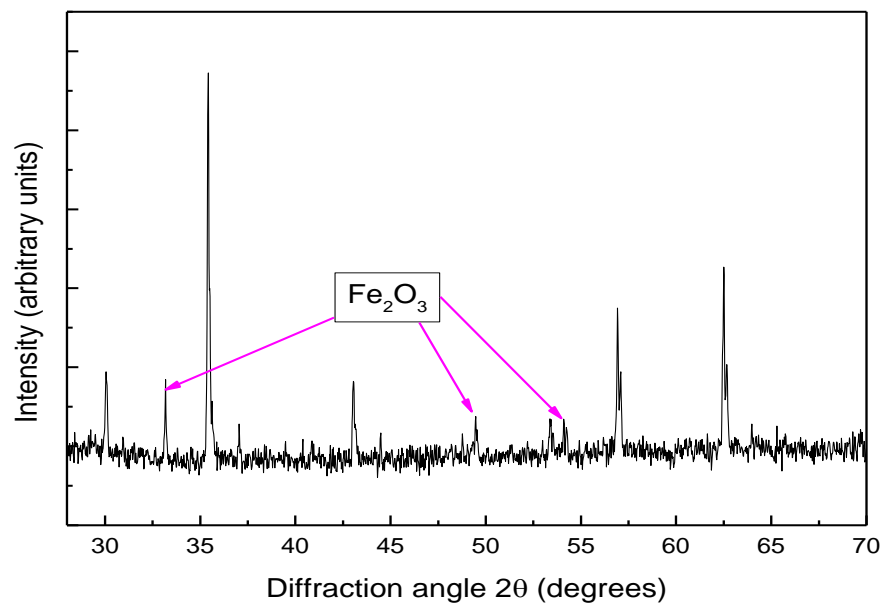

Figure 1. X-ray diffractogram of the sintered pellet.

Figures 2-3 show SEM images of the sintered pellet and Table 3 shows the compositions of the particles indicated in such figures. Phases with five different morphologies were observed in the microstructure:

(a) Large light-grey grains;

(b) Dark, sharp-faceted grey grains

(c) White round particles at grain boundaries

(d) White films at grain boundaries

(e) High aspect ratio light particles, surrounded by (d) particles.

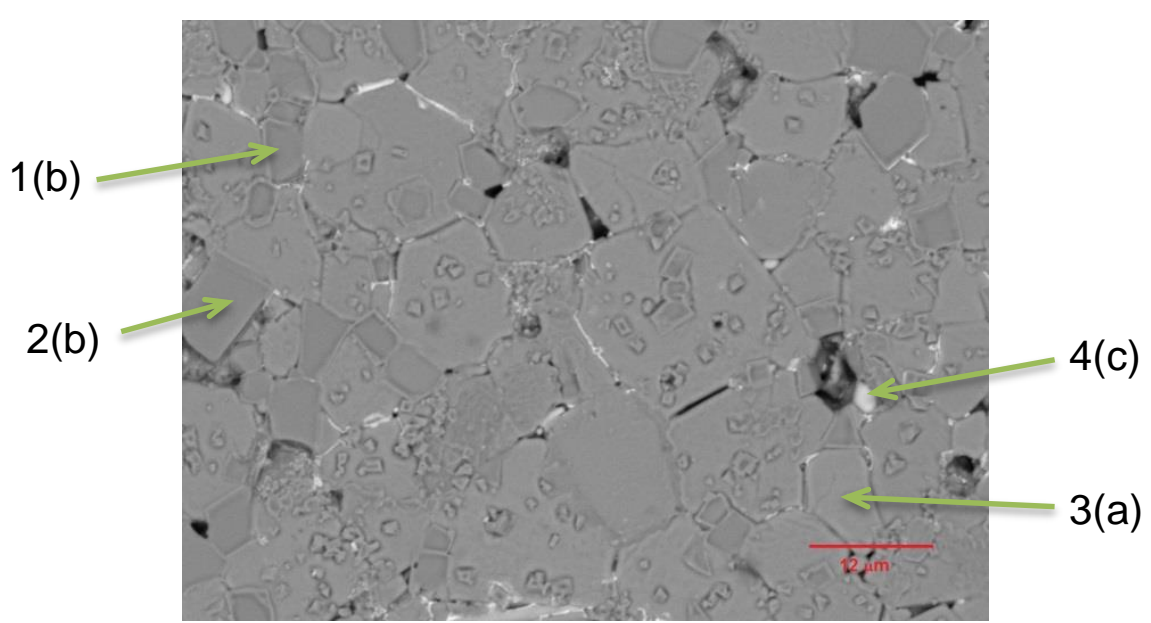

Figure 2. SEM image (BSE mode) of the sintered pellet, indicating particles of the types (a), (b), and (c). 


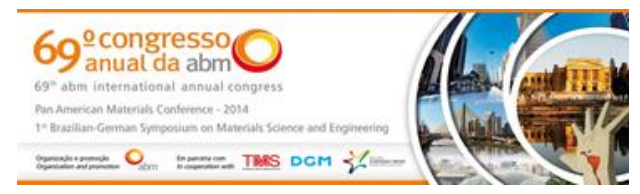

Figure 3. SEM image (BSE mode) of the sintered pellet, indicating particles of the types (d) and (e).

Table 3. Compositions (at.\%) of the phases indicated in Figs. 2 and 3, obtained from EDX analysis

\begin{tabular}{|c|c|c|c|c|c|}
\hline Element & $3(\mathrm{a})$ & $2(\mathrm{~b})$ & $4(\mathrm{c})$ & $5(\mathrm{~d})$ & $6(\mathrm{e})$ \\
\hline $\mathrm{O}$ & 63.01 & 65.66 & 64.20 & 56.22 & 68.12 \\
\hline $\mathrm{Mn}$ & 3.74 & 1.76 & 2.62 & 4.48 & 1.45 \\
\hline $\mathrm{Fe}$ & 23.31 & 30.17 & 19.03 & 27.58 & 9.70 \\
\hline $\mathrm{Co}$ & 9.93 & 2.41 & 5.64 & 10.43 & 3.09 \\
\hline $\mathrm{S}$ & - & - & 4.58 & - & - \\
\hline $\mathrm{Ba}$ & - & - & 3.93 & - & - \\
\hline $\mathrm{Bi}$ & - & - & - & 1.29 & 2.65 \\
\hline $\mathrm{Na}$ & - & - & - & - & 0.96 \\
\hline $\mathrm{Si}$ & - & - & - & - & 1.25 \\
\hline $\mathrm{P}$ & - & - & - & - & 5.87 \\
\hline $\mathrm{Ca}$ & - & - & - & - & 6.89 \\
\hline
\end{tabular}

Hu et al. [15] have shown that the decomposition of a Mn ferrite may occur in heattreatment temperatures between $550-1100^{\circ} \mathrm{C}$ when sintering in air. As a result from the decomposition process, $\mathrm{Fe}_{2} \mathrm{O}_{3}$ and $\mathrm{Mn}_{2} \mathrm{O}_{3}$ were formed in the ferrite produced by the authors. They also demonstrated that such decomposition did not occur when sintering in argon atmosphere. In our case, the long sintering time within such critical temperature range and the enhanced diffusion of liquid phase sintering favors this decomposition. In addition, the low sintering temperature used in liquid-phase sintering may impair the completion of the reactions to form the spinel phase, leaving a small fraction of unreacted $\mathrm{Fe}_{2} \mathrm{O}_{3}$.

According to Tab. 3, the Co:Mn:Fe atomic proportion of the spinel (a)-phase was $0.81: 0.30: 1.89$, evidencing the iron deficiency that resulted from the formation of $\mathrm{Fe}_{2} \mathrm{O}_{3}$. The composition of the matrix phase may affect the results obtained from an EDX analysis of a particle if it is thinner than the penetration depth of the electron beam. Thus, we suppose that the (b)-phase is mainly constituted of $\mathrm{Fe}_{2} \mathrm{O}_{3}$.

It was observed that the crystallized Bi-rich liquid phase formed intergranular films ((d)-particles). However, due to their small size, their composition measured by means of EDX was also influenced by the matrix.

The major contaminants from the raw materials tended to concentrate in intergranular particles. The $\mathrm{BaO}$ contamination of the manganese oxide used as raw material gave rise to the formation of $\mathrm{Ba} / \mathrm{S}$-rich precipitates (c) at grain boundaries, which are probably barium sulfide $(\mathrm{BaS})$. Since the melting/boiling point of $\mathrm{BaS}$ is $1200^{\circ} \mathrm{C}[16]$, this contaminant phase could also develop liquid phase during sintering

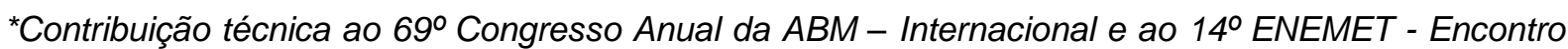
Nacional de Estudantes de Engenharia Metalúrgica, de Materiais e de Minas, 21 a 25 de julho de 2014, São Paulo, SP, Brasil. 


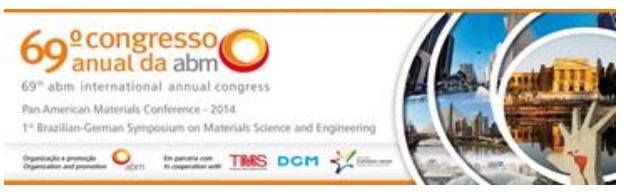

or volatilize at the temperatures normally used in solid state sintering $\left(1200-1400^{\circ} \mathrm{C}\right)$ : this would eliminate the $\mathrm{Ba}$ and $\mathrm{S}$ contamination. The minor contaminants $\mathrm{Na}, \mathrm{Si}, \mathrm{P}$, and $\mathrm{Ca}$ were detected in an elongated particle ((e)-particle), surrounded by (d)-type particles. The contaminants of lowest fractions $\mathrm{Mg}, \mathrm{Ni}, \mathrm{K}, \mathrm{Zn}$, and $\mathrm{Cr}$ weren't detected in none of the EDX analyses.

Figure 4 shows the magnetic hysteresis curve of the sintered sample. For Co0.7 $\mathrm{Mn}_{0.3} \mathrm{Fe}_{2} \mathrm{O}_{4}$, Bhame [10] found a saturation magnetization $\left(\mathrm{Ms}_{\mathrm{s}}\right)$ of $84.5 \mathrm{Am}^{2} / \mathrm{kg}$ and a coercive field $\left(\mathrm{H}_{\mathrm{c}}\right)$ of $56 \mathrm{Oe}\left(\right.$ or $\left.\mu_{0} \mathrm{H}_{\mathrm{c}}=22 \mathrm{mT}\right)$. That is, the sample presented in this work had inferior saturation magnetization, but had a significant reduction in coercivity, which is interesting for sensors applications.

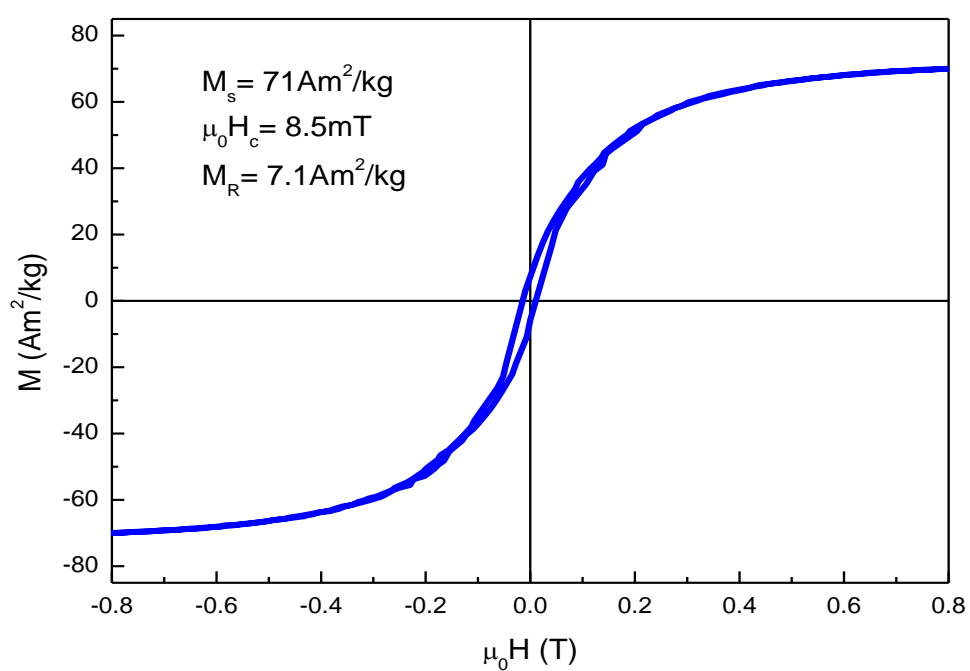

Figure 4. Magnetic hysteresis curve of the sintered sample.

Figure 5 shows the magnetostriction curves of the sintered sample and Fig. 6 shows the corresponding magnetoelastic sensitivity data. The geometry and dimensions of the sample affect the magnetoelastic sensitivity results. Thus for reducing the dimensional effects, the internal fields $\left(\mathrm{H}_{\text {int }}\right)$ at saturation were calculated by means of (2) and the results are also presented in Tab. 6. In (2), $\mathrm{N}$ is the geometrical factor [17], which determination is based on the samples' dimensions; $M$ is the magnetization at the field $\mathrm{H}$. For the determination of $\mathrm{N}$, the dimensions of the sample was approximated to a parallelepiped with squared section, obtaining $\mathrm{N}=0.289$.

$$
\mathrm{H}_{\text {int }}=\mathrm{H}-\mathrm{NM}
$$

Table 3 shows some parameters obtained from Figs. 5 and 6, including the maximum magnetoelastic sensitivities $\left(\mathrm{S}_{\mathrm{m}}\right)$ and the saturation field $\mathrm{H}_{\mathrm{s}}$.

For $0 \leq x \leq 0.4$, the total magnetostriction of the $\mathrm{Co}_{1-\mathrm{x}} \mathrm{Mn}_{\mathrm{x}} \mathrm{Fe}_{2} \mathrm{O}_{4}$ studied by Bhame [10] ranged from $-165 p p m$ to $-237 p p m$, indicating that the magnetostriction values of the sample here obtained have been impaired. However, they are still significant for sensors applications.

The magnetoelastic sensitivity data here obtained were compared to those obtained in our previous work on $\mathrm{CoFe}_{2} \mathrm{O}_{4}$ [11]. According to literature, the Mn substitution was expected to increase the magnetoelastic sensitivity of the Co ferrite, which $\left(\mathrm{S}_{\mathrm{m}}\right) / /$ ranged from 367 to $513 \mathrm{ppm} / \mathrm{T}$, depending on the microstructure [11]. However, the 


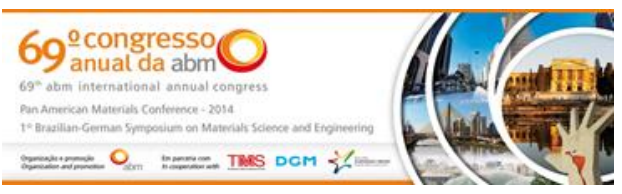

magnetoelastic sensitivity was reduced after Mn substitution and liquid-phase sintering.

The deterioration of the magnetostrictive properties of the Co-Mn ferrite may be attributed to the decomposition of the material, producing a spinel non-stoichiometric phase and a large amount of antiferromagnetic $\mathrm{Fe}_{2} \mathrm{O}_{3}$. According to our previous results [11], the presence of $\mathrm{Bi}_{2} \mathrm{O}_{3}$ in low fraction, which is diamagnetic, isn't expected to significantly affect the magnetic properties of the material.

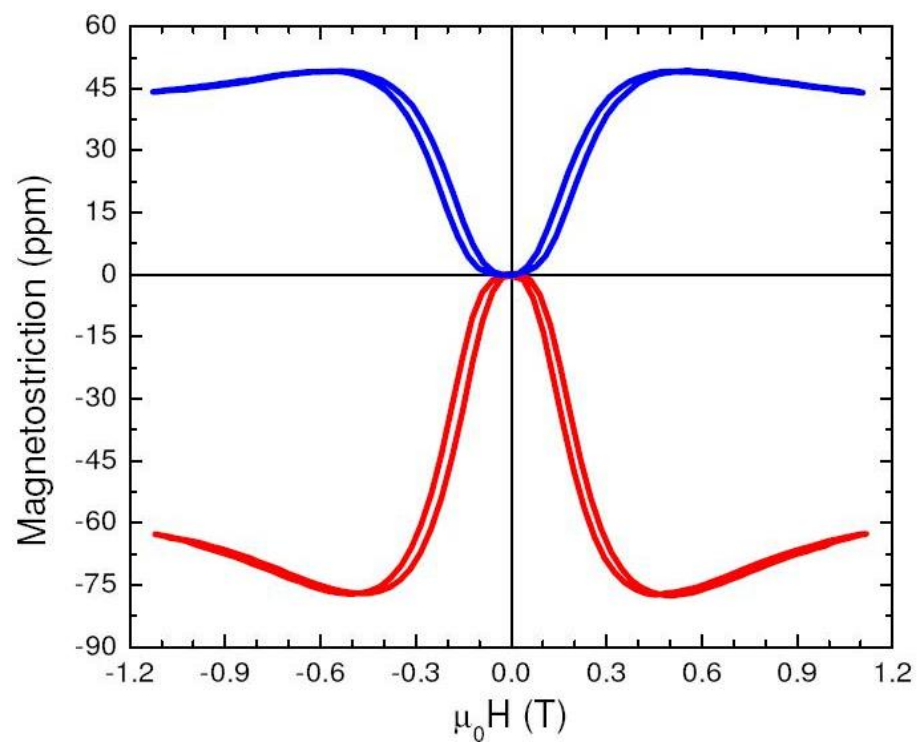

Figure 5. Magnetostriction curves of the sintered sample. Blue: $\lambda_{\perp}$; red: $\lambda / \%$

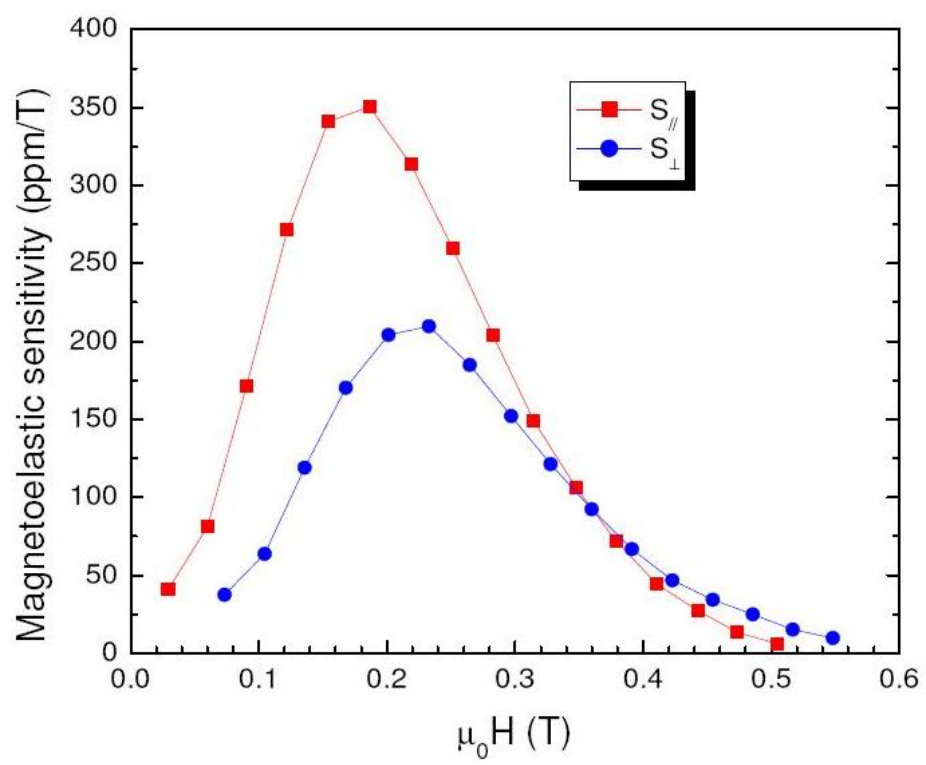

Figure 6. Magnetoelastic sensitivity of the sintered sample.

Table 3. Parameters obtained from the data presents in figures 5 and 6

\begin{tabular}{|r|c|}
\hline$\left(\lambda_{/ /}\right)_{\mathrm{s}}$ & $-77 \mathrm{ppm}$ \\
\hline$\left(\lambda_{\perp}\right)_{\mathrm{s}}$ & $49 \mathrm{ppm}$ \\
\hline$\left(\mathrm{S}_{\mathrm{m}}\right)_{\perp} ; \mu_{0} \mathrm{H}_{\text {int }}:$ & $210 \mathrm{ppm} / \mathrm{T} ; 0.100 \mathrm{~T}$ \\
\hline$\left(\mathrm{S}_{\mathrm{m}}\right)_{/ /} ; \mu_{0} \mathrm{H}_{\text {int }}:$ & $350 \mathrm{ppm} / \mathrm{T} ; 0.090 \mathrm{~T}$ \\
\hline Saturation field $\left(\mu_{0} \mathrm{H}_{\mathrm{s}}\right):$ & $0.425 \mathrm{~T}$ \\
\hline Total magnetostriction $\left(\lambda_{\text {tot }}\right):$ & $-126 \mathrm{ppm}$ \\
\hline
\end{tabular}

${ }^{*}$ Contribuição técnica ao $69^{\circ}$ Congresso Anual da ABM - Internacional e ao 14을 ENEMET - Encontro Nacional de Estudantes de Engenharia Metalúrgica, de Materiais e de Minas, 21 a 25 de julho de 2014, São Paulo, SP, Brasil. 


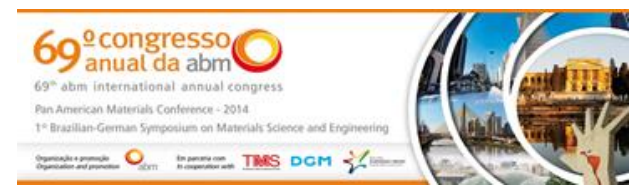

\section{CONCLUSION}

Liquid-phase sintering of a Co-Mn ferrite in air, with $\mathrm{Bi}_{2} \mathrm{O}_{3}$ as liquid phase former and $950^{\circ} \mathrm{C} / 24 \mathrm{~h}$ as sintering parameters, resulted in the decomposition of the ferrite into $\mathrm{Fe}_{2} \mathrm{O}_{3}$ and a spinel non-stoichiometric phase. Although still significant, the magnetostrictive properties of the sintered sample were inferior to the reported in literature for the target composition $\mathrm{Co}_{0.7} \mathrm{Mn}_{0.3} \mathrm{Fe}_{2} \mathrm{O}_{4}$; on the other hand, the coercivity of the sample was smaller than the expected. Thus, the sintering parameters, especially the sintering atmosphere, must be further adjusted in order to obtain chemically uniform sintered samples.

\section{Acknowledgements}

The authors acknowledge the financial support obtained from FAPESP (project no. 2009/09524-7), CNPq (scholarships) and CAPES.

\section{REFERENCES}

1 Paulsen AL, Ring AP, Lo CCH, Snyder JE, Jiles DC. Manganese-substituted cobalt ferrite magnetostrictive materials for magnetic stress sensor applications. Journal of Applied Physics, 2007; 97: 044502.

2 Atif M, Sato Turtelli R, Grossinger R, Kubel F. Influence of manganese substitution on the microstructure and magnetostrictive properties of $\mathrm{Co}_{1-x} \mathrm{Mn}_{x} \mathrm{Fe}_{2} \mathrm{O}_{4}(\mathrm{x}=0.0-0.4)$ ferrite. Journal of Applied Physics, 2013; 113: 153902.

3 khaja mohaideen K, Joy PA. High magnetostriction coefficient of Mn substituted cobalt ferrite sintered from nanocrystalline powders and after magnetic field annealing. Current Applied Physics, 2013; 13: 1697-1701.

4 Ranvah N, Nlebedim IC, Melikhov Y, Snyder JE, Jiles DC, Moses AJ et al. Temperature dependence of magnetostriction of $\mathrm{Co}_{1+\times} \mathrm{Ge}_{\times} \mathrm{Fe}_{2-2 \times} \mathrm{O}_{4}$ for magnetostrictive sensor and actuator applications. IEEE Transactions on Magnetics, 2008; 44(11): 3013-3016.

5 Nlebedim IC, Ranvah NM, Williams PI, Snyder JE, Jiles DC. Magnetic and magnetomechanical properties of $\mathrm{CoAl}_{x} \mathrm{Fe}_{2-\mathrm{x}} \mathrm{O}_{4}$ for stress sensor and actuator applications. IEEE Transactions on Magnetics, 2009; 45(10): 4120-4123.

6 Somaiah N, Jayaraman TV, Joy PA, Das D. Magnetic and magnetoelastic properties of $\mathrm{Zn}$-doped cobalt-ferrites- $\mathrm{CoFe}_{2-\mathrm{x}} \mathrm{Zn}_{\mathrm{x}} \mathrm{O}_{4}(\mathrm{x}=0,0.1,0.2$, and 0.3$)$. Journal of Magnetism and Magnetic Materials, 2012; 324: 2286-2291.

7 Song SH, Lo CCH, Lee SJ, Aldini ST, Snyder JE, Jiles DC. Magnetic and magnetoelastic properties of Ga-substituted cobalt ferrite. Journal of Applied Physics, 2007; 101: 09C517.

8 Caltun O, Rao GSN, Rao KH, Parvatheeswara RB, Dumitru I, Kim CO, Kim CG. The influence of Mn doping level on magnetostriction coefficient of cobalt ferrite. Journal of Magnetism and Magnetic Materials, 2007; 316: e618-e620.

9 Kambale RC, Shaikh PA, Harale NS, Bilur VA, Kolekar YD, Bhosale CH et al. Structural and magnetic properties of $\mathrm{Co}_{1-x} \mathrm{Mn}_{\mathrm{x}} \mathrm{Fe}_{2} \mathrm{O}_{4}(0 \leq \mathrm{x} \leq 0.4)$ spinel ferrites synthesized by combustion route. Journal of Alloys and Compounds, 2010; 490: 568-571.

10 Bhame S. Oxide magnetostrictive materials based on cobalt ferrite. Saarbrüken: Lambert Academic Publishing, 2011.

11 Brito VLO, Cunha SA, Lemos LV, Bormio-Nunes C. Magnetic properties of liquid-phase sintered $\mathrm{CoFe}_{2} \mathrm{O}_{4}$ for application in magnetoelastic and magnetoelectric transducers. Sensors, 2012; 12: 10086-10096. 


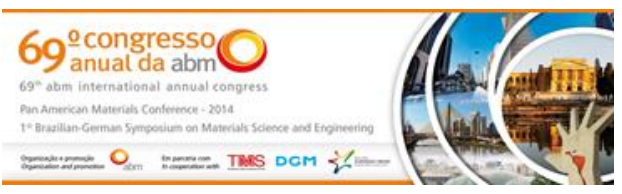

12 Santos CT. Evaluation of magnetostriction and microstructural characterization of Fe-Sn and Fe-V alloys. (Master's dissertation) Universidade de São Paulo, Escola de Engenharia de Lorena: Lorena, Brazil, 2008.

13 Smit J, Wijn HP. Ferrites. Eindhoven: Philips' Technical Library, 1959, p. 144.

14 Brito VLO, Cunha SA, Uchoas APR, Araújo FF, Bormio-Nunes C, Genova LA. Evaluation of the sinterability of copper-substituted ferrites by means of dilatometric thermal analysis. Proceedings of VI Conferência Brasileira sobre Temas de Tratamento Térmico. São Paulo: Metallum. Available at http://www.metallum.com.br/TTT2012/ANAIS/PDF/14-003.pdf. Cited in March 15 th 2014.

$15 \mathrm{Hu}$ P, Yang H, Pan D, Wang H, Tian J. Zhang et al. Heat treatment effects on microstructure and magnetic properties of $\mathrm{Mn}-\mathrm{Zn}$ ferrite powders. Journal of Magnetism and Magnetic Materials, 2010; 322: 173-177.

16 Barium \& Chemicals Inc. Barium sulfide safety and data sheet. Available at: http://www.bariumchemicals.com/Products/SDS_Printview3.asp?SDSid=17. Cited in 0131-2014.

17 Sato M, Ishii J. Simple and approximate expressions of demagnetizing factors of uniformly magnetized rectangular rod and cylinder. Journal of Applied Physics, 1989; (66): 983-986. 